\title{
The Relationship between Serum 25-Hydroxyvitamin D and Resistin Levels in Saudi Diabetic Patients
}

\author{
Ahmed El-Tahir ${ }^{*}$, Abdulaziz F. AL-Kaabbab², Muaawia Ahmed Hamza1, \\ Abdullah A. Saeed', Abdulshakour Abdalla1, May F. AlMohareb1, Hana S. Alfaleh', \\ Gwiria M. H. Satti ${ }^{1,3}$ \\ ${ }^{1}$ Faculty of Medicine, King Fahad Medical City, Ministry of Health, Kingdom of Saudi Arabia \\ ${ }^{2}$ Faculty of Medicine, Al-Imam Mohammed Ibn Saud Islamic University, Kingdom of Saudi Arabia \\ ${ }^{3}$ Faculty of Medicine, University of Khartoum, Sudan \\ Email: *ahmedeltahirm@yahoo.com
}

Received 10 January 2016; accepted 26 February 2016; published 29 February 2016

Copyright (C) 2016 by authors and Scientific Research Publishing Inc.

This work is licensed under the Creative Commons Attribution International License (CC BY). http://creativecommons.org/licenses/by/4.0/

(c) (7) Open Access

\section{Abstract}

Objectives: The aim of this study was to investigate the relationship between the levels of 25-hydroxyvitamin D and the adipokine resistin in Saudi diabetic patients and those at high risk to develop atherosclerotic cardiovascular diseases. Methodology: One hundred and sixty seven subjects were recruited for the cross-sectional study at King Fahad Medical City, Saudi Arabia. Blood samples were analyzed for biochemical parameters. Serum 25-hydroxyvitamin D and resistin levels were measured for all the participants. Result: Fifty six type-1, 55 type-2 diabetic patients and 56 healthy controls were recruited. Serum 25-hydroxyvitamin D level in the control group was 44.21 $\pm 41.80 \mu \mathrm{g} / \mathrm{ml}$ compared to $50.67 \pm 35.60 \mu \mathrm{g} / \mathrm{ml}$ in the diabetic group $(P=0.427)$ with no significant different between type- 2 diabetes mellitus and type-1 diabetes mellitus $(P=0.628)$. Resistin level in the control group was $14.00 \pm 7.39 \mu \mathrm{g} / \mathrm{ml}$ compared to $20.21 \pm 16.94 \mu \mathrm{g} / \mathrm{ml}$ in the diabetic group ( $P \leq 0.01)$, no significant difference between type-2 diabetes mellitus and type-1 diabetes mellitus ( $P=0.817)$. Resistin in those taking vitamin $D$ supplementation was $21.34 \pm 18.27 \mu \mathrm{g} / \mathrm{ml}$; and in those not taking vitamin $D$ supplementation, it was $17.4 \pm 11.19 \mu \mathrm{g} / \mathrm{ml} ;(P=0.237)$. There was significant negative correlation between 25 -hydroxyvitamin $D$ and resistin in type-2 diabetes mellitus ( $P \leq 0.043)$ and no significant correlation was found between vitamin $25(\mathrm{OH}) \mathrm{D}$ and resistin level in type-1 diabetes mellitus $(P=0.538)$. Blood urea and creatinine showed significant positive correlation with vitamin $25(\mathrm{OH}) \mathrm{D}$ in one hand and resistin level on the other hand. Discussion and Conclusions: Several in vitro and in vivo studies have confirmed that the vitamin 25 (OH) D have numerous important functions in the body. The circulating vitamin $25(\mathrm{OH}) \mathrm{D}$ and re-

\footnotetext{
${ }^{*}$ Corresponding author.
} 
sistin levels were associated with general inflammation in renal diseases. This study showed significant negative correlation between resistin level and vitamin $25(\mathrm{OH}) \mathrm{D}$ in type 2 diabetes mellitus reflecting their roles in glucose homeostasis. The positive correlation of resistin and vitamin D with urea may reflect their involvement in kidney dysfunction. The level of serum resistin showed slight increase in diabetic patients compared to control group and it was higher in type-2 diabetes mellitus. More efforts are needed to explore the physiological mechanism of vitamin 25 $(\mathrm{OH}) \mathrm{D}$ and resistin action in metabolic disorders.

\section{Keywords}

\section{5-Hydroxyvitamin D, Resistin, Diabetes Mellitus, Kingdom of Saudi Arabia}

\section{Introduction}

There is growing evidence that vitamin D deficiency can be a contributing factor in the development of both type 1 and type 2 diabetes [1]-[4]. Vitamin D might function as an immune and insulin secretion modulator [5] and had also been shown to down regulate the production of several cytokines in in vitro studies [6]. Additionally, vitamin D might also provide protection against major health problems such as autoimmune disease, cardio-metabolic disease, and cancer [7] [8]. It also remains unclear if vitamin D deficiency is associated with insulin resistance and if there is a role for vitamin $\mathrm{D}$ replacement in the treatment of glucose intolerance. Hormones such as the adipokines; adiponectin and resistin are a possible link between insulin resistance and adiposity. Furthermore, several clinical and epidemiological studies have revealed positive associations between plasma concentrations of resistin and pro-inflammatory cytokines in diabetics and coronary heart diseases [10]-[12]. Another study done by Vilarrasa [9] in a healthy population showed no significant associations between plasma concentrations of $25(\mathrm{OH})$ D and resistin whereas plasma $25(\mathrm{OH})$ D showed a negative correlation with body mass index-body fat, waist, hip circumference and with leptin. National surveys in Kingdom of Saudi Arabia (KSA) reported an increasing prevalence of diabetes and obesity affecting more than a quarter of the adult population [13]-[15]. Also in Kingdom of Saudi Arabia, more than 50\% of the population suffer from hypovitaminosis $\mathrm{D}(<50 \mathrm{nmol} / \mathrm{l})$ [16]. To further evaluate whether vitamin D deficiency is associated with diabetes mellitus and changes of adipokine secretion especially resistin, we measured serum $25(\mathrm{OH}) \mathrm{D}$ concentrations and resistin level for Saudi diabetic patients and those at high risk to develop atherosclerotic cardiovascular diseases. Such assessment will predict the individuals at high risk to develop complications, taking into account a comprehensive list of risk factors, including age, obesity and hyperlipidemia.

\section{Subjects and Methodology}

This study is a cross-sectional, health facilities-based study, conducted in central state, Kingdom of Saudi Arabia during April 2012-September 2013. Patients are diagnosed as type-1 or type-2 Diabetes Mellitus according to the WHO classification (1999) and fulfilling the set criteria for enrollment as exclusion of pregnant women. One hundred and eleven diabetic patients; 52 males and 59 females, were enrolled in the study. Fifty six were recruited as age and sex matched healthy controls. Written consents were obtained and investigations were conducted according to the principles expressed in the Declaration of Helsinki. Blood; $5 \mathrm{ml}$, was collected from each participant in plain vacutainers and serum was separated after centrifugation and stored at $-20^{\circ} \mathrm{C}$ till analysis.

Demographic and clinical data of the study groups were collected through a questionnaire filled by patients prior to samples collection. Weight and height of participants were measured and BMI was calculated.

\subsection{Laboratory Investigations}

Glycated haemoglobin was measured from venous blood samples collected following overnight fast using the chromatographic based method [17]. Triglycerides and high-density lipoprotein cholesterol (HDL-C) were determined by enzymatic methods. 25-hydroxyvitamin D was measured by specific ELISAs in accordance with 
the instructions provided by the manufacturer (IDS, Tyne \& Wear, UK). Serum resistin on fasting blood was measured using a human resistin Quantikine ELISA kit Cat DRSNOO (R \& D Systems, UK) following the manufacturer's protocol.

\subsection{Statistical Analysis}

Parametric (mean + standard deviation (SD) and nonparametric measurements were calculated using SPSS package version 18 windows. Correlation coefficient and T-test was used and $\mathrm{P} \leq 0.05$ was considered as significant.

\section{Result}

One hundred and eleven diabetics and 56 healthy controls were recruited in this study. The mean age of the diabetic group was ( $33.29 \pm 23.13)$ and the mean duration of diabetes mellitus was $(8.61 \pm 7.27)$ year and the body mass index (BMI) was (27.42 \pm 10.1$)$.

Table 1 shows the levels of vitamin $25(\mathrm{OH}) \mathrm{D}$ and resistin in the study group. Serum resistin level in the diabetic group was higher than that of the control group $(\mathrm{P}<0.001)$.

Table 2 shows the mean \pm standard deviation (SD) of biochemical parameters in diabetic groups. BMI was higher in DM type-2 and lower in DM type-1 compared to the reference values; while glycated haemgolobin was higher than the reference values in the 2 groups. The liver enzymes are in the normal range for the study group. For lipid prolife, only triacyglycerol showed higher result than the reference value in the 2 diabetic groups. Biochemical parameters for kidney function test, creatine is normal while the plasma urea levels are to the upper reference values.

Table 1. The level of vitamin $25(\mathrm{OH}) \mathrm{D}$ and resistin levels in the study group.

\begin{tabular}{ccc}
\hline Group & Vitamin $25(\mathrm{OH}) \mathrm{D}($ total $) \mathrm{nmol} / \mathrm{ml}$ & Resitin $\mu \mathrm{g} / \mathrm{ml}$ \\
\hline Control & $44.21 \pm 41.80$ & $14.00 \pm 7.39$ \\
DM & $50.67 \pm 35.60$ & $20.21 \pm 16.94$ \\
DM type-1 & $51.67 \pm 36.98$ & $19.44 \pm 17.05$ \\
DM typ-2 & $48.41 \pm 34.54$ & $21.71 \pm 16.52$ \\
\hline
\end{tabular}

Table 2. Biochemical parameters in the Study groups (mean \pm SD).

\begin{tabular}{cccc}
\hline Parameters & Control & DM type-2 & DM-type-1 \\
\hline Age (year) & $30.45 \pm 13.5$ & $52.3 \pm 17.1$ & $14.6 \pm 8.2$ \\
Duration of the disease (year) & - & $10.4 \pm 8.5$ & $7.3 \pm 5.9$ \\
BMI & $28.9 \pm 11.9$ & $33.1 \pm 10.7$ & $22.12 \pm 5.7$ \\
HB A1c \% & $6.1 \pm 1.1$ & $8.9 \pm 2.0$ & $10.0 \pm 1.7$ \\
LDH (U/L) & $1.86 \pm 0.87$ & $2.62 \pm 0.77$ & $2.84 \pm 0.89$ \\
AST (U/L) & - & $31.4 \pm 58.5$ & $34.0 \pm 28.2$ \\
ALT (SGPT) (U/L) & $33.0 \pm 0.0$ & $38.9 \pm 13.2$ & $49.0 \pm 26.8$ \\
Alkaline phosphatase (U/L) & $82.0 \pm 0.0$ & $104.6 \pm 32.0$ & $234 \pm 119.2$ \\
Triacylglycerol (mmol/L) & $0.97 \pm 0.04$ & $2.08 \pm 1.4$ & $1.84 \pm 1.42$ \\
Total cholesterol (mmol/L) & $3.55 \pm 0.49$ & $4.39 \pm 0.95$ & $4.46 \pm 1.22$ \\
LDL cholesterol (mmol/L) & $1.86 \pm 0.87$ & $2.62 \pm 0.77$ & $2.84 \pm 0.89$ \\
HDL-cholesterol (mmol/L) & $1.4 \pm 0.07$ & $1.07 \pm 0.27$ & $1.17 \pm 0.43$ \\
TSH mlU/L) & $5.09 \pm 2.2$ & $3.09 \pm 2.7$ & $4.08 \pm 5.17$ \\
T4 (pmol/L) & $15.85 \pm 2.2$ & $15.24 \pm 2.3$ & $16.18 \pm 2.19$ \\
Creatinine ( $\mu$ mol/L) & $59.0 \pm 0.0$ & $83.2 \pm 37.8$ & $62.3 \pm 22.25$ \\
Urea (mmol/L & $3.3 \pm 0.0$ & $5.87 \pm 3.7$ & $4.59 \pm 1.9$ \\
Calcium (mmol/L) & - & $2.33 \pm 0.12$ & $2.3 \pm 0.118$ \\
\hline
\end{tabular}


Table 3 shows vitamin D and resistin levels in diabetic complications. The highest level of resistin was for nephropathy, neuropathy and cardiopathy while the lowest was found in hyperlipidemia. There is significant difference in the resistin level between cardiopathy, nephropathy and retinopathy compared to the healthy control. The level of vitamin $25(\mathrm{OH}) \mathrm{D}$ was also high in patients with hyperlipidemia and neuropathy and the lowest was found in nephropathy, this may explain the role of kidney function on vitamin D levels.

Table 4 shows the level of resistin level and vitamin $25(\mathrm{OH}) \mathrm{D}$ accordingly to the gender, positive family history of diabetes mellitus, statin medication and vitamin $25(\mathrm{OH})$ D supplementation. Vitamin $25(\mathrm{OH})$ D levels showed genetic link $(\mathrm{P}=0.006)$ with positive family history for the first degree relative whereas resistin showed non-significant genetic link $(\mathrm{P}=0.07)$. In this study, no significant increase for resistin and vitamin $\mathrm{D}$ levels was found with vitamin D supplementation or taking statins; the cholesterol lowering drugs. There is weak correlation between resistin level and hypertension and strong correlation between incidence of hypertension and hyperlipidemia and the use of statin drugs $\mathrm{P}$ values $\leq 0.0001$.

Table 5 shows the correlation of plasma vitamin $25(\mathrm{OH}) \mathrm{D}$ and resistin with biochemical parameters. There is significant negative correlation between resistin level and vitamin $25(\mathrm{OH}) \mathrm{D}$ in type 2 diabetes mellitus reflecting the roles of vitamin D in type-2 diabetes mellitus (P value 0.043 ). Vitamin $25(\mathrm{OH}) \mathrm{D}$ level showed significant positive correlation with creatinine and urea (P-values $0.018,0.036)$ respectively. Whereas resistin level showed profound, non-significant correlation $(\mathrm{P}=0.078)$ with calcium level. All other biochemical parameters including lipid profile were not significantly correlated with plasma resistin or vitamin $25(\mathrm{OH}) \mathrm{D}$ level.

\section{Discussion}

This cross-sectional study which was intended to explore whether there is a relationship between $25^{\prime}$ (OH) vitamin $\mathrm{D}$ and serum resistin levels among diabetic patients that might affect the severity of the disease. The study showed that vitamin $25(\mathrm{OH}) \mathrm{D}$ level was at the bottom of the normal range in the control and the diabetic groups. The life style of Saudi subjects such as no sun exposure and the high body fat mass which leads to limited bioavailability of vitamin $\mathrm{D}$ caused by the trapping of vitamin $\mathrm{D}$ in adipose tissue may further increase the

Table 3. Resistin and vitamin $25(\mathrm{OH})$ D levels with diabetic complications.

\begin{tabular}{cccc}
\hline Complications & Number & Vitamin $25(\mathrm{OH}) \mathrm{D}$ & Resistin \\
\hline Neuropathy & 9 & $52.72 \pm 43.4$ & $26.26 \pm 17.59$ \\
Nephropathy & 14 & $47.9 \pm 25.01$ & $25.16 \pm 20.42$ \\
Retinopathy & 23 & $50.85 \pm 35.01$ & $23.33 \pm 16.34$ \\
Cardiopathy & 22 & $48.50 \pm 37.55$ & $25.44 \pm 16.6$ \\
Hyperlipidemia & 44 & $54.58 \pm 33.00$ & $19.93 \pm 33.00$ \\
Hypertension & 42 & $51.43 \pm 40.1$ & $24.13 \pm 20.8$ \\
\hline
\end{tabular}

Table 4. Resistin and vitamin $25(\mathrm{OH})$ D levels accordingly to gender, family history of diabetes, statin medication and vitamin $25(\mathrm{OH}) \mathrm{D}$ supplementation.

\begin{tabular}{|c|c|c|c|c|}
\hline & Vitamin $25(\mathrm{OH}) \mathrm{D}$ & P-value & Resistin level & P-value \\
\hline Male & $48.08 \pm 32.31$ & \multirow{2}{*}{0.591} & $19.58 \pm 14.9$ & \multirow{2}{*}{0.264} \\
\hline Female & $51.74 \pm 39.6$ & & $21.54 \pm 18.16$ & \\
\hline $\begin{array}{l}\text { Positive family history (first } \\
\text { degree relative) }\end{array}$ & $41.04 \pm 23.11$ & \multirow[t]{2}{*}{0.006} & $20.61 \pm 17.68$ & \multirow[t]{2}{*}{0.07} \\
\hline Negative family history & $66.38 \pm 33.23$ & & $9.99 \pm 5.09$ & \\
\hline Taking statin drugs & $50.85 \pm 32.68$ & \multirow{2}{*}{0.638} & $19.94 \pm 15.99$ & \multirow{2}{*}{0.2} \\
\hline Not taking statin drugs & $47.77 \pm 33.01$ & & $20.17 \pm 17.01$ & \\
\hline Vitamin D supplementation & $48.83 \pm 35.51$ & \multirow[b]{2}{*}{0.474} & 21.34 & \multirow[b]{2}{*}{0.273} \\
\hline $\begin{array}{c}\text { Without vitamin } 25(\mathrm{OH}) \text { D sup- } \\
\text { plementation }\end{array}$ & $54.15 \pm 37.51$ & & 17.41 & \\
\hline
\end{tabular}


Table 5. The correlation between vitamin $25(\mathrm{OH}) \mathrm{D}$ and resistin with biochemical parameters in diabetes mellitus type-2 (P-values).

\begin{tabular}{ccccc}
\hline & \multicolumn{2}{c}{ Vitamin 25 (OH) D } & \multicolumn{2}{c}{ Resistin } \\
\cline { 2 - 4 } & $\begin{array}{c}\text { Diabetes mellitus } \\
\text { type-2 }\end{array}$ & $\begin{array}{c}\text { Diabetes mellitus } \\
\text { type-1 }\end{array}$ & $\begin{array}{c}\text { Diabetes mellitus } \\
\text { type-2 }\end{array}$ & $\begin{array}{c}\text { Diabetes mellitus } \\
\text { type-1 }\end{array}$ \\
HbA1c & 0.231 & 0.113 & 0.231 & $0.047^{*}$ \\
Total cholesterol & 0.79 & $0.024^{*}$ & 0.797 & 0.336 \\
LDL-cholesterol & 0.77 & 0.098 & 0.767 & 0.225 \\
HDL-cholesterol & 0.937 & 0.937 & 0.937 & 0.984 \\
Triacylglycerol & 0.412 & 0.412 & 0.412 & 0.561 \\
AST & 0.318 & 0.921 & 0.318 & 0.569 \\
ALT & 0.202 & 0.202 & 0.202 & 0.775 \\
LDH & 0.375 & 0.407 & 0.101 & 0.670 \\
Creatinine & $0.018^{*}$ & 0.197 & $0.018^{*}$ & 0.694 \\
Urea & $0.036^{*}$ & $0.036^{*}$ & $0.013^{*}$ & 0.424 \\
Calcium & 0.90 & 0.424 & 0.943 & \\
Resistin & $0.043^{*}$ & 0.538 & $0.043^{*}$ & 0.538 \\
Vitamin 25 (OH) D & & & \\
\hline
\end{tabular}

${ }^{*} \mathrm{P}$ value $\leq 0.05$

risk of vitamin D deficiency. Therefore it is possible that vitamin D deficiency may contribute to insulin resistance and the development of metabolic syndrome secondary to inflammation aggravated by the increased resistin levels in diabetics. Our results revealed that the level of serum resistin slightly increases among diabetic patients compared to the control group $(\mathrm{P} \leq 0.061)$. Given the obesity-insulin resistance-inflammation link and convergence of adipocyte and macrophage function, resistin may provide unique insight into links between obesity, inflammation, and metabolic syndrome risk in humans. This connection between macrophage derived resistin and adipose tissues may further clarify the understanding of obesity as an inflammatory state and implicates resistin as a potential modulator of that state. Vitamin D has been shown to inhibit antigen-induced T cell proliferation and cytokine production [18], acting as an immune-modulatory agent [19]. Recently, vitamin D has been proposed to also have anti-inflammatory properties. Interestingly, the serum resistin level among patient with type 2 diabetes was found to be higher than those of type 1 and non-diabetic control. Serum resistin level in this study showed to be much higher level in neuropathy and nephropathy compared to the other complications, whereas vitamin $25(\mathrm{OH})$ D was slightly increased in hyperlipidemia and neuropathy. Hyperlipidemia showed lower resistin level compared to the other complications. This may reflect the effect of hypolipidemic drugs on circulating resistin in diabetic subjects and slight increase in vitamin $25(\mathrm{OH}) \mathrm{D}$. Blood urea and creatinine showed significant correlation with the resistin level and vitamin $25(\mathrm{OH}) \mathrm{D}$, while vitamin $25(\mathrm{OH})$ D showed negative correlation with resistin in type- 2 diabetes mellitus. The role of low vitamin $25(\mathrm{OH}) \mathrm{D}$ and increased resistin as pro-inflammatory may affect the kidneys dysfunction. Thus circulating vitamin $25(\mathrm{OH}) \mathrm{D}$ and resistin levels were associated with general inflammation, and renal disease. Our findings do not fully support the hypothesis that vitamin $\mathrm{D}$ deficiency is associated with poorer glycemic control which can be caused by $\beta$-cell dysfunction as well as insulin resistance as there was no correlation between HB A1c and vitamin D level $(\mathrm{P}=$ 0.874). On the other hand the effect of vitamin $\mathrm{D}$ on diabetes might be mediated through the increased serum resistin level at decreased levels of vitamin $25(\mathrm{OH}) \mathrm{D}$ as seen in type-2 diabetes mellitus through negative correlation between resistin and vitamin $\mathrm{D}$ in the present study. This effect would be influenced by obesity while such correlation was not detected in type-1 diabetes mellitus or non-diabetic study group.

\section{Conclusion}

This study showed significant negative correlation between vitamin $25(\mathrm{OH}) \mathrm{D}$ and resistin level in type-2 di- 
abetes mellitus. The correlation of vitamin $\mathrm{D}$ and resistin with urea may reflect their involvement in kidney dysfunction and the circulating vitamin $25(\mathrm{OH}) \mathrm{D}$ and resistin levels are associated with general inflammation in renal diseases. The level of serum resistin showed slight increase in diabetic patients compared to control group and it was higher in type-2 diabetes mellitus. More efforts are needed to explore the physiological mechanism of vitamin $25(\mathrm{OH}) \mathrm{D}$ and resistin action in metabolic disorders.

\section{Recommendations}

To investigate the impact of vitamin D treatment in diabetic and the role of vitamin D on glucose homeostasis and resistin as an inflammatory marker, future studies should use highly sensitive measures of insulin sensitivity and $\beta$-cell serum markers as well as other inflammatory markers.

\section{Limitations}

The cross-sectional nature of the study and the small sample size limits the findings of the study. Several major confounders were also not included including season which has a counterintuitive effect in the vitamin D status of citizens residing in the Gulf region [20].

\section{Ethical Consideration}

The project was reviewed and approved by the Institutional Review board-IRP King Fahad Medical City, Log number 11-040. All patients were consented before their enrollment in the study.

\section{Acknowledgements}

This study was funded by SRC, Faculty of Medicine, King Fahad Medical City under grant no.10/32/1.

\section{References}

[1] Bland, R., Markovic, D., Hills, C.E. and Hughes, S.V. (2004) Expression of 25-Hydroxyvitamin D3-1 Alpha-Hydroxylase in Pancreatic Islets. The Journal of Steroid Biochemistry and Molecular Biology, 121, 89-90. http://dx.doi.org/10.1016/s0960-0760(04)00149-9

[2] Parekh, D., Sarathi, V., Shivane, V.K., Bandgar, T.R., Menon, P.S. and Shah, N.S. (2010) Pilot Study to Evaluate the Effect of Short-Term Improvement in Vitamin D Status on Glucose Tolerance in Patients with Type 2 Diabetes. Endocrine Practice 16, 600-608. http://dx.doi.org/10.4158/EP09300.OR

[3] Von Hurst, P.R., Sonehouse, W. and Coad, J. (2010) Vitamin D Supplementation Reduces Insulin Resistance in South Asian Women Living in New Zealand Who Are Insulin Resistant and Vitamin D Deficient: A Randomized, Placebo-Controlled Trial. British Journal of Nutrition, 103, 549-555. http://dx.doi.org/10.1017/S0007114509992017

[4] Bourlon, P.M., Billaudel, B. and Faure-Dussert, A. (1999) Influence of Vitamin D3 Deficiency and 1,25-Dihydroxyvitamin D3 on Denovo Insulin Biosynthesis in the Islets of the Rat Endocrine Pancreas. Journal of Endocrinology, 160, 87-95. http://dx.doi.org/10.1677/joe.0.1600087

[5] Van Etten, E. and Mathieu, C. (2005) Immunoregulation by 1,25-Dihydroxyvitamin $\mathrm{D}_{3}$ : Basic Concepts. The Journal of Steroid Biochemistry and Molecular Biology, 97, 93-101. http://dx.doi.org/10.1016/j.jsbmb.2005.06.002

[6] Khoo, A.L., Chai, L.Y.A., Koenen, H.J.P.M., Sweep, F.C.G.J., Joosten, I., Netea, M.G. and van der Ven, A.J.A.M. (2011) Regulation of Cytokine Responses by Seasonality of Vitamin D Status in Healthy Individuals. Clinical \& Experimental Immunology, 164, 72-79. http://dx.doi.org/10.1111/j.1365-2249.2010.04315.X

[7] Dusso, A.S., Brown, A.J. and Slatopolsky, E. (2005) Vitamin D. American Journal of Physiology, 289, F8-F28. http://dx.doi.org/10.1152/ajprenal.00336.2004

[8] de Boer, I.H., Kestenbaum, B., Shoben, A.B., Michos, E.D., Sarnak, M.J. and Siscovick, D.S. (2009) 25-Hydroxyvitamin D Levels Inversely Associate with Risk for Developing Coronary Artery Calcification. Journal of the American Society of Nephrology, 20, 1805-1812. http://dx.doi.org/10.1681/ASN.2008111157

[9] Vilarrasa, N., Vendrell, J., Maravall, J., Elío, I., Solano, E., San José, P., García, I., Virgili, N., Soler, J. and Gómez, J.M. (2010) Is Plasma 25(OH) D Related to Adipokines, Inflammatory Cytokines and Insulin Resistance in Both a Healthy and Morbidly Obese Population? Endocrine, 38, 235-242.

[10] Osawa, H., Onuma, H., Ochi, M., et al. (2005) Resistin SNP-420 Determines Its Monocyte mRNA and Serum Levels Inducing Type 2 Diabetes. Biochemical and Biophysical Research Communications, 335, 596-602. 
http://dx.doi.org/10.1016/j.bbrc.2005.07.122

[11] Tsukahara, T., Nakashima, E., Watarai, A., et al. (2009) Polymorphism in Resistin Promoter Region at -420 Determines the Serum Resistin Levels and May Be a Risk Marker of Stroke in Japanese Type 2 Diabetic Patients. Diabetes Research and Clinical Practice, 84, 179-186. http://dx.doi.org/10.1016/j.diabres.2008.10.021

[12] Burnett, M.S., Devaney, J.M., Adenika, R.J., et al. (2006) Cross-Sectional Associations of Resistin, Coronary Heart Disease, and Insulin Resistance. The Journal of Clinical Endocrinology \& Metabolism, 91, 64-68. http://dx.doi.org/10.1210/jc.2005-1653

[13] AL-Nozha, M.M., AL-Mmatouq, M.A., AL-Mazrou, Y.Y. and AL-Harthi, S.S. (2004) A Diabetes Mellitus in Saudi Arabia. Saudi Medical Journal, 25, 1603-1610.

[14] ALqurashi, K., Aljabri, K.S. and Bokari, S.A. (2011) Prevalence of Diabetes Mellitus in a Saudi Community. Ann Saudi Med, 31, 19-23.

[15] Patel, L., Buckels, A.C., Kinghorn, I.J., et al. (2003) Resistin Is Expressed in Human Macrophages and Directly Regulated by PPAR Gamma Activators. Biochemical and Biophysical Research Communications, 300, 472-476. http://dx.doi.org/10.1016/S0006-291X(02)02841-3

[16] Aljohani, N.J., Al-Daghri, N.M., Al-Attas, O.S., Alokail, M.S., Alkhrafy, K.M., Al-Othman, A., et al. (2013) Differences and Associations of Metabolic and Vitamin D Status among Patients with and without Sub-Clinical Hypothyroid Dysfunction. BMC Endocrine Disorders, 13, 31. http://dx.doi.org/10.1186/1472-6823-13-31

[17] Maquart, F.-X., Gillery, P., Bernard, J.-F., Mante, J.-P. and Borel, J.-P. (1980) A Method for Specifically Measuring Haemoglobin $\mathrm{A}_{\mathrm{IC}}$ with a Disposable Commercial Ion-Exchange Column. Clinica Chimica Acta, 108, 329-332. http://dx.doi.org/10.1016/0009-8981(80)90021-2

[18] Bhalla, A.K., Amento, E.P., Serog, B. and Glimcher, L.H. (1984) 1,25-Dihydroxyvitamin D3 inhibits Antigeninduced $\mathrm{T}$ Cell Activation. Journal of Immunology, 133, 1748-1754.

[19] Mathieu, C. and Adorini, L. (2002) The Coming of Age of 1,25-Dihydroxyvitamin D(3) Analogs as Immunomodulatory Agents. Trends in Molecular Medicine, 8, 174-179. http://dx.doi.org/10.1016/S1471-4914(02)02294-3

[20] Al-Daghri, N.M., Al-Attas, O.S., Alokail, M.S., Alkharfy, K.M., El-Kholie, E., Yousef, M., Al-Othman, A., Al-Saleh, Y., Sabico, S., Kumar, S. and Chrousos, G.P. (2012) Increased Vitamin D Supplementation Recommended during Summer Season in the Gulf Region: A Counterintuitive Seasonal Effect in Vitamin D Levels in Adult, Overweight and Obese Middle Eastern Residents. Clinical Endocrinology, 76, 346-350. http://dx.doi.org/10.1111/j.1365-2265.2011.04219.x 